\title{
PENTINGNYA KONSEP DASAR K3 DALAM PEMBERIAN ASUHAN \\ KEPERAWATAN KEPADA PASIEN DI RUMAH SAKIT
}

\author{
Kiki Dwi Febriyanti \\ kiifeb83@gmail.com
}

\section{LATAR BELAKANG}

Rumah sakit umum adalah rumah sakit ang memberikan pelayanan kesehatan pada semua bidang dan jenis penyakit. Pelaanan rumah sakit merupakan bagian yang tidak terpisah dari system pelayanan kesehatan pada umumnya. Dalam pemberian pelayanan kesehatan, rumah sakit diharapkan dapat memberikan pelayanan yang berkualitas. Potensi bahaya di rumah sakit dapat disebabkan oleh factor biologis, factor kimia, factor ergonomic, factor fisik, factor psikososial, bahaya mekanik, bahaya listrik, limbah rumah sakit, ang dapat mengancam jiwa dan kehidupan bagi para karyawan rumah sakit, pasien maupun para pengunjung ang ada di lingkungan rumah sakit yang mengakibatkan penyakit dan kecelakaan kerja.

Kesehatan dan Keselamatan Kerja (K3) merupakan suatu upaya perlindungan kepada tenaga kerja dan orang lain yang memasuki tempat kerja terhadap bahaya dari akibat kecelakaan kerja. Tujuan K3 adalah mencegah, megurangi, bahkan menihilkan resiko penyakit dan kecelakaan akibat kerja (KAK) serta meningkatkan derajat kesehatan para pekerja sehingga produktivitas kerja meningkat. Dalam Undang-Undang Republik Indonesia Nomor 36 Tahun 2009 Tentang Kesehatan, upaya kesehatan kerja ditunjukkan untuk melindungi pekerja agar hidup sehat dan terbebas dari gangguan kesehatan serta pengaruh buruk yang diakibatkan oleh pekerjaan sehingga sudah seharusnya pihak pengelola rumah sakit menerapkan upaya-upaya K3 di rumah sakit. K3 termasuk sebagai salah satu standar pelayanan yang dinilai di dalam akreditasi rumah sakit, disamping standar pelayanan lainnya.

Pekerja rumah sakit mempunyai risiko lebih tinggi dibanding pekerja industri lain untuk terjadinya Penyakit Akibat Kerja (PAK) dan KAK, sehingga perlu dibuat standar perlindungan bagi pekerja yang ada di rumah sakit. Untuk mencegah dan mengurangi resiko bahaya tersebut maka perlu ditetapkan standar K3 di rumah sakit. 
Perlunya pelaksanaan K3RS mengenai kebijakan pemerintah tentang rumah sakit di Indonesia adalah untuk meningkatkan akses, keterjangkauan, dan kualitas pelayanan kesehatan yang aman di rumah sakit. Perencanaan, pelaksanaan, monitoring, dan evaluasi K3 RS serta tindak lanjut, yang merujuk pada SK Menkes No. 432/ Menkes/ SK/ IV/ 2007 tentang Pedoman Manajemen K3 di RS dan OHSAS 18001 tentang Standar Sistem Manajemen K3. Sistem manajemen K3RS adalah bagian dari sistem manajemen rumah sakit.

Pelaksanaan K3, berkaitan dengan citra dan kelangsungan hidup rumah sakit. Manajemen adalah proses perencanaan, pengorganisasian, pengarahan dan pengawasan usaha para anggota organisasi dan pengguanaan sumber daya organisasi lainnya agar mencapai tujuan organisasi yang telah ditetapkan. Kementerian Kesehatan Republik Indonesia mewajibkan dilaksanakannya akreditasi rumah sakit dengan tujuan untuk meningkatkan pelayanan rumah sakit di Indonesia. Standar akreditasi yang digunakan saat ini akan menekankan pada pelayanan berfokus pada pasien serta kesinambungan pelayanan dan menjadikan keselamatan pasien sebagai standar utama serta melibatkan seluruh petugas dalam proses akreditasi.

\section{METODE}

metode yang digunakan dalam penulisan ini adalah metode kajian bebas dimana metode ini berwilayah lebih sempit dengan tingkat variasi yang rendah, namun dari penulisan ini dapat berkembang menjadi lebih luas. Metode kajian bebas ini merupakan metode yang dilakukan untuk melakukan penulisan yang dikumpulkan dari beberapa sumber seperti buku teks, buku referensi jurnal dan e-book, dan juga dibandingkan dengan jurnal yang berhubungan dengan "pentingnya peran keluarga dalam pencegahan pasien di rumah sakit". Sehingga pembaca dapat mengerti informasi yang sudah ditulis dan dapat memahami pentingnya peran keluarga dalam pencegahan pasien di rumah sakit.

\section{HASIL}

Rumah sakit merupakan perusahaan yang memiliki kegiatan operasional jasa pelayanan kesehatan bagi masyarakat dimana sangat membutuhkan tenaga kerja yang berkualitas, untuk mencapai tujuan yang diharapkan oleh pihak rumah sakit maka dapat dilakukan dengan cara membentuk suatu kepuasan kerja pada perawatnya. Dengan adanya kepuasan 
kerja perawat maka diharapkan mereka dapat menjalankan tugasnya dengan baik. Untuk mampu menciptakan tingkat pelayanan yang berkualitas dibutuhkan perawat yang memiliki kualitas pula kemampuan untuk menarik dan menpertahankan tenaga kerja yang berkualitas dan cakap merupakan kebutuhan prasyarat sukses bagi sebuah perusahaan. reputasi perusahaan merupakan modal pokok yang mencerminkan pada kemampuan perusahaan untuk memuaskan ke Keselamatan dan kesehatan kerja (K3) adalah suatu program yang dibuat pekerja maupun pengusaha sebagai upaya mencegah timbulnya kecelakaan akibat kerja dan penyakit serta tindakan antisipatif apabila terjadi kecelakaan dan penyakit kerja. Tujuannya adalah untuk menciptkan tempat keja yang nyaman, dan sehat sehingga dapat menekan serendah mungkin resiko kecelakaan dan penyakit. Adapun mengenai tujuan keselamatan dan kesehatan kerja (K3) dijelaskan pula oleh suatu undang-undang semata memberikan jamian kepada karyawan dari perusahaan itu sendiri dan juga meningkatkan kesejateraan secara bersama yang dapat menjalankan produktifitas dalam bidang usaha yang telah dikelolanya secara baik sehingga dapat mencapai tujuan dari perusahaan itu sendiri.
Perkembangan pengelolaan rumah sakit baik dari aspek manajemen maupun operasional sangat dipengaruhi oleh berbagai tuntutan baik lingkungan internal maupun eksternal. Tuntutan internal seperti memberikan kesejahteraan untuk staf dan perkembangan teknologi untuk menunjang pelayanan rumah sakit itu sendiri. Sedangkan tuntutan eksternal antara lain rumah sakit dituntut untuk memberikan pelayanan yang bermutu dan biaya pelayanan yang terkendali yang berujung pada kepuasan pelayanan itu sendiri.

Kepuasan kerja dari setiap tenaga perawat dapat diukur dari besar kecilnya kesenjangan antara harapan yang diinginkan dengan kenyataan yang diterimanya. Semakin kecil kesenjangan antara harapan dengan kenyataan , semakin besar pula tingkat kepuasan kerja yang dirasakan oleh tenaga perawat. Keselamatan kerja dapat mempengaruhi tingkat kepuasan karyawan. Hal tersebut disebabkan apa bila karyawan mendapatkan perlindungan keselamatan kerja dari perusahan, maka karyawan akan merasa aman, sehingga karyawan memiliki kepuasan terhadap perusahaan. Sedangkan Hubungan antara kepuasan kerja dengan kesehatan fisik dan mental. Kajian yang dilakukan korhauser tentang kesehatan mental dan kepuasan kerja adalah untuk 
semua tingkatan jabatan, persepsi dari tenaga kerja bahwa pekerjaan mereka menuntut penggunaan efektif dari kemampuan mereka berkaitan dengan skor kesehatan. Skor ini juga berkaitan dengan tingkat dari kepuasan kerja dan tingkat dari jabatan. Tingkat dari kepuasan kerja dan kesehatan saling mengukuhkan sehingga dapat meningkatkan satu dengan yang lainnya dan dapat melakukan penuruan yang satu mempunyai akibat yang negatif juga yang lain (Ashar Sunyoto, 2008).

\section{PEMBAHASAN}

\section{Definisi K3 (Kesehatan dan Keselamatan kerja)}

Kesehatan dan Keselamatan Kerja (K3) adalah suatu program yang dibuat sebagai upaya mencegah timbulnya kecelakaan dan penyakit akibat kerja dengan cara mengenali hal-hal yang berpotensi menimbulkan kecelakaan dan penyakit akibat kerja serta tindakan antisipatif apabila terjadi kecelakaan dan penyakit akibat kerja. Upaya penanganan faktor potensi berbahaya yang ada di rumah sakit serta metode pengembangan program kesehatan dan keselamatan kerja perlu dilaksanakan, seperti misalnya perlindungan baik terhadap penyakit infeksi maupun non-infeksi, penanganan limbah medis, penggunaan alat pelindung diri dan lain sebagainya.

Selain terhadap pekerja di fasilitas medis/klinik maupun rumah sakit, kesehatan dan keselamatan kerja di rumah sakit juga "concern" keselamatan dan hakhak pasien, yang masuk kedalam program patient safety. Selama ini ruang lingkup Keselamatan dan Kesehatan Kerja (K3) selalu dihubungkan dengan proses industri dengan resiko tinggi (high risk industry), seperti pabrik dan pertambangan. Tidak banyak yang tahu bahwa K3 juga mendapat posisi penting di industri pelayanan kesehatan seiring dengan dikeluarkannya Keputusan Menteri Kesehatan RI No.1087/MENKES/SK/VIII/2010.

Melalui Kemenkes ini telah ditetapkan standar penerapan K3 untuk Rumah Sakit (RS) atau disingkat K3RS.

Tujuan dari dibentukna K3 di rumah sakit ialah untuk menyelenggarakan keselamatan dan Kesehatan Kerja di Rumah Sakit secara optimal, efektif, efisien dan berkesinambungan.

\section{Kecelakaan Kerja}

Keselamatan kerja berkaitan dengan kecelakaan kerja, yaitu kecelakaan yang terjadi di tempat kerja. Pengertian kecelakaan adalah cacat dan kematian sebagai akibat kecelakaan kerja. 
kecelakaan akibat kerja berhubungan dengan hubungan kerja pada perusahaan. Hubungan kerja disini dapat berarti bahwa kecelakaan terjadi dikarenakan oleh pekerjaan atau pada waktu melaksanakan pekerjaan. Maka dalam hal ini kecelakaan adalah akibat langsung pekerjaan atau kecelakaan terjadi pada saat pekerjaan sedang dilakukan (Suma'mur, 2009). Terjadinya kecelakaan kerja disebabkan oleh faktor manusia dan faktor fisik. Faktor manusia yang tidak memenuhi keselamatan misalnya kelengahan, kecerobohan, mengantuk, dan kelelahan sedangkan kondisi lingkungan yang tidak aman misalnya lantai licin, pencahayaan kurang, silau, dan mesin terbuka (Notoatmodjo, 2007). Kecelakaan kerja tidak saja menimbulkan korban jiwa maupun kerugian materi bagi pekerja dan pengusaha, tetapi juga dapat mengganggu proses produksi secara menyeluruh, merusak lingkungan yang pada akhirnya akan berdampak pada masyarakat luas (Kepmenkes RI No. 1087 tahun 2010).

Keselamatan dan kesehatan kerja merupakan hal yang penting bagi perusahaan, karena dampak kecelakaan dan penyakit kerja tidak hanya merugikan karyawan, tetapi juga perusahaan baik secara langsung maupun tidak langsung (Kusuma, 2001). Sasaran utama dari K3 ditujukan terhadap perawat, dengan melakukan segala daya upaya berupa pencegahan, pemeliharaan dan peningkatan kesehatan tenaga kerja, agar terhindar dari risiko buruk di dalam melakukan pekerjaan.

Potensi KAK yang terbesar disebabkan kesalahan atau kelalaian dari karyawan yang tidak menggunakan APD dalam bekerja. Walaupun pengawas sudah memberitahukan dan menyarankan menggunakan APD dapat menghindari terjadinya KAK, tetapi masih ada karyawan yang tidak menghiraukannya. Bahkan pengawas juga tidak memberikan sanksi atau teguran karena karyawan merasa kurang nyaman atau kurang dapat bergerak secara leluasa saat bekerja.

Indikator Keselamatan dan Kesehatan Kerja (K3) Menurut (Dessler:1997)

indikator kesehatan karyawan terdiri dari :

1. Keadaan dan Kondisi Karyawan Keadaan dan kondisi karyawan adalah keadaan yang dialami oleh karyawan pada saat bekerja yang mendukung aktifitas dalam bekerja.

2. Lingkungan kerja Lingkungan kerja adalah lingkungan yang lebih luas dari tempat kerja yang mendukung aktifitas karyawan dalam bekerja.

3. Perlindungan karyawan Perlindungan karyawan merupakan fasilitas yang 
diberikan untuk menunjang kesejahteraan karyawan.

Menurut (Suma'ar:1986) adapun indikator - indikator keselamatan kerja meliputi :

4. Tempat kerja Adalah merupakan lokasi dimana para karyawan melaksanakan aktifitas kerjanya.

5. Mesin dan peralatan Adalah bagian dari kegiatan operasional dalam proses produksi yang biasanya berupa alatalat berat dan ringan.

Fungsi seorang perawat sangat tergantung kepada kebijaksanaan rumah sakit dalam hal luasnya ruang lingkup usaha kesehatan, susunan dan jumlah tenaga kesehatan yang dipekerjakan dalam rumah sakit. Perawat merupakan satu-satunya tenaga kesehatan yang full time berada di rumah sakit, maka fungsinya diantaranya adalah memelihara dan mempertinggi mutu pelayanan perawatan, membantu dokter dalam pemeriksaan kesehatan sesuai caracara yang telah disetujui, ikut membantu menentukan kasus-kasus penderita, serta berusaha menindaklanjuti sesuai wewenang yang diberikan kepadanya, membantu usaha perbaikan kesehatan lingkungan dan rumah sakit sesuai kemampuan yang ada, turut ambil bagian dalam usaha keselamatan kerja, mengumpulkan data-data dan membuat laporan untuk statistic dan evaluasi, turut membantu dalam usaha penyelidikan kesehatan tenaga kerja, memelihara hubungan yang harmonis dalam rumah sakit, memberikan penyuluhan dalam bidang kesehatan, dll.

Keselamatan dan kesehatan kerja adalah upaya untuk memberikan jaminan keselamatan dan meningkatkan derajat kesehatan para pekerja dengan cara pencegahan kecelakaan dan penyakit akibat kerja, pengendalian bahaya di tempat kerja, promosi kesehatan, pengobatan dan rehabilitasi. Peran kesehatan dan keselamatan kerja dalam ilmu kesehatan kerja berkontribusi dalam upaya perlindungan kesehatan para pekerja dengan upaya promosi kesehatan, pemantauan, dan survei kesehatan serta upaya peningkatan daya tahan tubuh dan kebugaran pekerja. Sementara peran keselamatan adalah menciptakan sistem kerja yang aman atau yang mempunyai potensi risiko yang rendah terhadap terjadinya kecelakaan dan menjaga aset perusahaan dari kemungkinan loss (Rejeki, 2015).

sebagian besar perawat pelaksana memiliki perilaku yang baik dalam penerapan manajemen Kesehatan dan Keselamatan Kerja (K3) baik ditinjau dari faktor internal (52.5\%) maupun faktor eksternal (58.8\%). Semua faktor yang dapat menentukan atau membentuk 
perilaku manusia disebut determinan

perilaku. Determinan perilaku manusia terdiri dari faktor internal dan faktor eksternal. Faktor internal yaitu karakteristik dari individu yang bersangkutan yang bersifat bawaan sedangkan faktor eksternal yaitu faktor yang berasal dari luar diri seseorang (Notoatmodjo, 2010).

faktor motivasi dan persepsi dapat mempengaruhi kepatuhan perawat dalam pelaksanaan asuhan keperawatan yang sesuai dengan SOP. Perawat dengan persepsi baik memiliki kemungkinan lebih besar untuk patuh dibandingkan dengan perawat dengan persepsi kurang.

\section{PENUTUP}

\section{Kesimpulan}

Keselamatan dan kesehatan kerja adalah upaya untuk memberikan jaminan keselamatan dan meningkatkan derajat kesehatan para pekerja dengan cara pencegahan kecelakaan dan penyakit akibat kerja, pengendalian bahaya di tempat kerja, promosi kesehatan, pengobatan dan rehabilitasi. Perawat merupakan satu-satunya tenaga kesehatan yang full time berada di rumah sakit, maka fungsinya diantaranya adalah memelihara dan mempertinggi mutu pelayanan perawatan, membantu dokter dalam pemeriksaan kesehatan sesuai caracara yang telah disetujui, ikut membantu menentukan kasus-kasus penderita, serta berusaha menindaklanjuti sesuai wewenang yang diberikan kepadanya, membantu usaha perbaikan kesehatan lingkungan dan rumah sakit sesuai kemampuan yang ada, turut ambil bagian dalam usaha keselamatan kerja, mengumpulkan data-data dan membuat laporan untuk statistic dan evaluasi, turut membantu dalam usaha penyelidikan kesehatan tenaga kerja, memelihara hubungan yang harmonis dalam rumah sakit, memberikan penyuluhan dalam bidang kesehatan, dll. Selain terhadap pekerja di fasilitas medis/klinik maupun rumah sakit, kesehatan dan keselamatan kerja di rumah sakit juga "concern" keselamatan dan hak-hak pasien, yang masuk kedalam program patient safety.

\section{Saran}

Adapun saran dari peneliti untuk profesi keperawatan sebaiknya terus mengembangkan pengetahuan dan keterampilan di bidang manajemen keperawatan khususnya terkait Kesehatan dan Keselamatan Kerja (K3) sehingga pelayanan yang diberikan dapat lebih optimal dan berkualitas tanpa melupakan tingkat kesehatan dan 
keselamatan bagi pemberi asuhan keperawatan.

\section{DAFTAR PUSTAKA}

Bando, J. J., Kawatu, P. A., \& Ratag, B. T. (2020).

GAMBARAN

PENERAPAN

PROGRAM

KESELAMATAN

DAN

KESEHATAN KERJA RUMAH

SAKIT (K3RS) DI RUMAH

SAKIT

ADVENT

MANADO. Kesmas, 9(2).

Effendy, S. W. (2013). STRATEGI PENGEMBANGAN SISTEM MANAJEMEN K3 PADA RUMAH SAKIT UMUM DAERAH KAYUAGUNG KABUPATEN OGAN KOMERING ILIR. Sustainable Competitive Advantage (SCA), 3(1).

Ernawati, N., \& Nurlelawati, E. (2017). FAKTOR-FAKTOR YANG BERHUBUNGAN DENGAN
PELAKSANAAN PENERAPAN

K3 PADA TENAGA

KESEHATAN DI RSIA

PERMATA SARANA

HUSADA PERIODE

FEBRUARI 2015. Jurnal

Akademi Keperawatan Husada

Karya Jaya, 3(1).

Kurniawidjaja, L. M. (2007). FILOSOFI

DAN KONSEP DASAR KESEHATAN KERJA SERTA PERKEMBANGANNYA

DALAM PRAKTIK. Kesmas:

National Public Health

Journal, 1(6), 243-251.

Mulyatiningsih, S. (2013).

DETERMINAN PERILAKU

PERAWAT DALAM

MELAKSANAKAN

KESELAMATAN PASIEN DI RAWAT INAP RSAU DR. ESNAWAN ANTARIKSA JAKARTA. Tesis (Publish). Fakultas Ilmu Keperawatan. Depok.

Rejeki, S. (2015). SANITASI, HIGIENE DAN KESELAMATAN KERJA (K3). Bandung: Rekayasa Sains.

Salawati, L., Taufik, H. N., Putra, A. (2014). ANALISIS TINDAKAN KESELAMATAN DAN KESEHATAN KERJA 
PERAWAT

DALAM

PENGENDALIAN INFEKSI

NOSOKOMIAL DI RUANG

ICU RSUD DR. ZAINOEL

ABIDIN BANDA ACEH.

Volume 14, Nomor 3.

Simamora, R. H. (2011). ROLE CONFLICT OF NURSE RELATIONSHIP WITH PERFORMANCE IN THE EMERGENCY UNIT OF HOSPITALS RSD DR. SOEBANDI JEMBER. The Malaysian Journal of Nursing, 3(2), 23-32.

Tukatman., Sulistiawati., Purwaningsih., \& Nursalam. (2015). ANALISIS KESELAMATAN DAN KESEHATAN KERJA PERAWAT DALAM PENANGANAN PASIEN DI RUMAH SAKIT BENYAMIN GULUH KABUPATEN KOLAKA. Jurnal Ners Vol. 10 No. 2.

Ekowati, A. D. (2009). UPAYA PENGENDALIAN FAKTOR BAHAYA BIOLOGIS DI INSTALASI RAWAT INAP I BAGIAN PENYAKIT DALAM RSUP DR. SARDJITO YOGYAKARTA. 